\title{
Autonomy of Growth and of lodine Metabolism in Hyperthyroid Feline Goiters Transplanted onto Nude Mice
}

Hans J. Peter, Hans Gerber, Hugo Studer, David V. Becker, ${ }^{*}$ and Mark E. Peterson* Department of Internal Medicine, University of Bern, Inselspital, CH-3010 Bern, Switzerland; *Division of Nuclear Medicine, The New York Hospital-Cornell Medical Center, New York 10021; ${ }^{\ddagger}$ Department of Medicine, The Animal Medical Center and Center for Research Animal Resources, Cornell University Medical College, New York 10021

\begin{abstract}
Hyperthyroidism caused by nodular goiters is a common disease of aging cats. Growth and iodine metabolism were studied by autoradiography in normal and hyperfunctioning thyroid tissue obtained from cats injected with ${ }^{125}$ I before surgery, and in xenografts, grown in nude mice, after double-labeling with ${ }^{131} I$ and $\left[{ }^{3} \mathbf{H}\right]$ thymidine.

Hyperthyroid cat goiters contain single or multiple hyperplastic nodules, consisting of highly cellular tissue with an iodine metabolism exceeding that of the surrounding normal tissue. Xenografts of hyperplastic hot tissue in thyroxine-treated nude mice retain their original histologic pattern and continue to accumulate radioiodine intensely. Autoradiographs assessed for $\left[{ }^{3} \mathbf{H}\right]$ thymidine incorporation reveal autonomously proliferating follicular cells within the hyperplastic foci but not within the normal tissue. Administration of sera from donor cats into host mice fails to stimulate the xenografts.

Neither hyperfunction nor growth of toxic cat goiters depends on extrathyroidal stimulators. The basic lesion appears to be an excessive intrinsic growth capacity of some thyroid cells.
\end{abstract}

\section{Introduction}

Although the clinical picture and laboratory features of feline hyperthyroidism were first thoroughly described only a few years ago $(1,2)$, this disorder now represents a well established clinical entity in veterinary medicine $(3,4)$. Cats are the only nonhuman mammalian species in which spontaneous hyperthyroidism develops at frequencies high enough to allow investigations of the pathogenesis of thyroid hyperfunction.

Earlier studies have revealed that feline hyperthyroid goiters contain multiple hyperplastic nodules (2). However, the pathogenetic processes causing focal hyperplasia remain unknown. To further characterize toxic feline goiters, normal and hyperthyroid cat thyroid glands were labeled with ${ }^{125} \mathrm{I}$ and iodine organification assessed autoradiographically on serial histological sections of the surgically removed thyroids. In a second series of experiments, normal thyroid tissue and toxic goiters were transplanted onto nude $\mathrm{nu} / \mathrm{nu}$ mice and labeled with $\left[{ }^{3} \mathrm{H}\right]$ thymidine and ${ }^{131} \mathrm{I}$ for autoradiographic evaluation of follicular cell function and growth. The latter series was aimed at

Address reprint requests to Dr. Peter. Dr. Gerber is a Special Fellow of the Kamillo Eisner Stiftung, Hergiswil, Switzerland.

Received for publication 2 December 1986 and in revised form 13 March 1987.

J. Clin. Invest

(C) The American Society for Clinical Investigation, Inc.

0021-9738/87/08/0491/08 \$2.00

Volume 80, August 1987, 491-498 determining whether hyperplasia and hyperfunction develop in response to extrathyroidal stimulating factors present only in the diseased cat or if the excessive growth is, on the contrary, a truly autonomous phenomenon intrinsic to the cells.

\section{Methods}

Preoperative ${ }^{125}$ I labeling. In the first set of experiments, 7 cats with clinically overt hyperthyroidism and 10 normal cats from New York were studied. Serum concentrations of L-thyroxine $\left(T_{4}\right)^{1}$ and L-triiodothyronine $\left(\mathrm{T}_{3}\right)$ were determined using commercial radioimmunoassay (RIA) kits (Micromedic Systems, Horsham, PA). All cats with toxic nodular goiter had elevated serum levels of $\mathrm{T}_{4}(8.4$ to $22.1 \mu \mathrm{g} / \mathrm{dl}$, normal $=0.8$ to $4.0 \mu \mathrm{g} / \mathrm{dl})$ and $\mathrm{T}_{3}(154$ to $444 \mathrm{ng} / \mathrm{dl}$, normal $=25$ to $125 \mathrm{ng} /$ $\mathrm{dl}$ ) at the time of surgery. Preoperative preparation for the hyperthyroid cats included either methimazole $(15 \mathrm{mg} / \mathrm{d})$ or propranolol $(7.5 \mathrm{mg} / \mathrm{d})$. In those cats treated with methimazole, the drug was stopped and propranolol substituted at least $3 \mathrm{~d}$ before the administration of the radioiodine label to ensure a hyperthyroid state at time of thyroid removal. Each cat was injected intravenously with $20 \mu \mathrm{Ci}^{125} \mathrm{I} 1$ to $72 \mathrm{~h}$ before surgery. In both normal and hyperthyroid cats anesthesia was induced with intravenous thiobarbiturate and maintained with inhaled methoxyfluorane and nitrous oxide. Uptake of ${ }^{125} \mathrm{I}$ by the excised thyroid glands was measured using a gamma counting system (MR 480, Kontron, Zurich, Switzerland) and calculated per milligram of tissue weight.

For autoradiography and histological examination, tissue was fixed

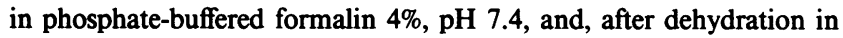
graded series of alcohols, embedded in methacrylate (JB-4 embedding mixture, Polysciences, Inc., Warrington, PA); 3- $\mu \mathrm{m}$ sections were mounted on glass slides, dipped in NTB-2 nuclear emulsion (Eastman Kodak Co., Rochester, NY), developed with Kodak D-19 developer after appropriate exposure time and counterstained with nuclear fast red (5). Additional sections were stained with periodic acid Schiff (PAS). Up to 12 serial sections were examined for each sample.

Xenotransplantation. In a second series of experiments, goiter tissue from 6 hyperthyroid cats not previously labeled with ${ }^{125}$ I was transplanted onto nude nu/nu ICR mice kept under specific pathogen free conditions in a 12-h light/12-h dark cycle. The surgically removed goiter tissue was carefully cut into small fragments (3-5 mm diam) and immediately immersed in RPMI 1640 containing $100 \mathrm{IU}$ of penicillin and $100 \mu \mathrm{g}$ streptomycin per $\mathrm{ml}$ (Gibco, Grand Island, NY), cooled on ice to $0^{\circ} \mathrm{C}$ and shipped by air freight from New York to Zurich. Fragments measuring $\sim 3 \times 1 \mathrm{~mm}$ were implanted subcutaneously onto 72 mice (three fragments per animal) by means of a trocar as previously described in detail (6). Xenotransplantation was completed within $20 \mathrm{~h}$ after removal of the goiter tissue. Additional fragments from each goiter were processed for histological examination.

The grafts were allowed to grow in the recipient mice for 4-6 wk. After that time the grafted animals were given L-thyroxine $\left(T_{4}\right.$, Fluka AG, Buchs, Switzerland), at a concentration of $0.5 \mu \mathrm{g} / \mathrm{ml}$ in the drinking water (daily $\mathrm{T}_{4}$-intake of $\sim 2.5 \mu \mathrm{g}$ ), to suppress endogenous thyroidstimulating hormone (TSH) ${ }^{1}$ secretion. After $1 \mathrm{wk}$, the animals bearing

1. Abbreviations used in this paper: $\mathrm{T}_{3}, \mathrm{~L}$-triiodothyronine; $\mathrm{T}_{4}, \mathrm{~L}$-thyroxine; $\mathrm{TSH}$, thyroid-stimulating hormone. 
tissue of a single toxic cat goiter were divided into two groups. Group A was injected with serum from the donor cat $(0.25 \mathrm{ml} /$ animal per day), group B with $\mathrm{NaCl}(0.25 \mathrm{ml}, 0.9 \%)$ for $5 \mathrm{~d}$. In mice bearing normal thyroid tissue a third group (C) was formed that was treated with bovine TSH $100 \mathrm{mU}$ i.p. daily (Ambinon, Organon, Oss, The Netherlands). The animals were labeled either with ${ }^{125} \mathrm{I}, 10 \mu \mathrm{Ci}$ i.p. $3 \mathrm{~h}$ before killing under chloroform anesthesia or with $\left[{ }^{3} \mathrm{H}\right]$ thymidine, $3 \times 10 \mu \mathrm{Ci}$ i.p. daily for $5 \mathrm{~d}$, and with $20 \mu \mathrm{Ci}$ of ${ }^{131} \mathrm{I} 3 \mathrm{~h}$ before death. Transplants and mice thyroids were processed for measurement of the radioiodine uptake and for serial semiquantitative autoradiographs according to the procedures described above for cat thyroid tissue reported in more details elsewhere (6). Since the recipient mouse's thyroid was processed and exposed for autoradiography in strictly the same way as the grafts, the relative grain density over each tissue, which is proportional to its uptake, can be visually compared and semiquantitatively assessed. For $\left[{ }^{3} \mathrm{H}\right]$ thymidine autoradiographs, ${ }^{131} \mathrm{I}$ was allowed to decay for $3 \mathrm{mo}$.

\section{Results}

Histologic features of feline goiters. On histologic examination, all thyroid lobes collected from cats with hyperthyroidism contained one or more, well discernible foci of hyperplastic tissue, sometimes forming nodules ranging in size from $<1 \mathrm{~mm}$ to 3 $\mathrm{cm}$. The size of the cells as well as the volume of the nuclei were invariably much larger within the hyperplastic tissue than the surrounding tissue. The hyperplastic follicles were lined by a columnar epithelium and contained faintly PAS positive colloid (Fig. 1). Follicular size varied considerably between different nodules; whereas in some nodules tiny follicles or even an almost solid growth pattern was prevalent, large follicles had formed in others. Even within an individual nodule there was pronounced variability of follicular architecture. Determination of the numerical density of follicular cell nuclei by stereological assessment (7) as well as by DNA measurement (8) revealed on the average two to three times more follicular cells per unit of volume in the hyperplastic nodules than in the nonhyperplastic normal tissue. Since the cells were also larger than normal, the total volume of the cell mass was even more than three times higher in nodular than in nonnodular tissue. Extranodular tissue was built up by colloid-rich follicles lined by a flat epithelium. Often, some of the nodules compressed the surrounding extranodular tissue while others did not (Fig. 1). In none of the toxic goiters was there any evidence of infiltration with lymphocytes.

Of particular interest were some tiny nests of cuboidal cells that appeared to represent the earliest stage of a hyperplastic focus (Fig. 2). Zones of smooth transition between normal and hyperplastic tissue were commonly seen. In such areas it became difficult to distinguish the two types of tissue.

Autoradiographic investigations. Based on the average grain count per unit of tissue volume, autoradiographs from toxic cat goiters labeled with ${ }^{125}$ I before surgery showed intense accumulation of radioiodine within the hyperplastic nodules, whereas in the adjacent normal areas iodine organification was low (Fig. 3). However, such increased radioiodine accumulation did not invariably apply to individual follicles, in which uptake varied from nil to very intense. Marked heterogeneity of iodine uptake was also found in the normal feline thyroid (data not shown). Specimens taken before $4 \mathrm{~h}$ after administration of radioiodine, (i.e., before the newly iodinated thyroglobulin molecules had completely distributed within the colloid) displayed marked heterogeneity of thyroglobulin iodination even among the cells of individual follicles. This is in line with the view that the amount of iodine turned over by any follicle is a function of the relative distribution of highly and poorly iodinating cells within that follicle (6).

Xenotransplantation. Grafts of cat thyroids were remarkably well tolerated by the nude mice. Most transplants grew without any signs of necrosis. Histologically, goiter grafts were exact replicas of the donor tissue; hyperplastic, highly cellular areas with micro- or normofollicular structure retained exactly the same growth pattern in the recipient mouse as did the extranodular tissue consisting of colloid rich follicles lined by flat epithelial cells (Fig. 4). Despite suppression of the mouse's TSH secretion and consequent depression of the mouse thyroid uptake, intense organification of radioiodine was found in the hyperplastic, nodular grafts of the cat goiter, whereas it was much lower in the extranodular colloid-rich follicles (Figs. 5, 6). However, as

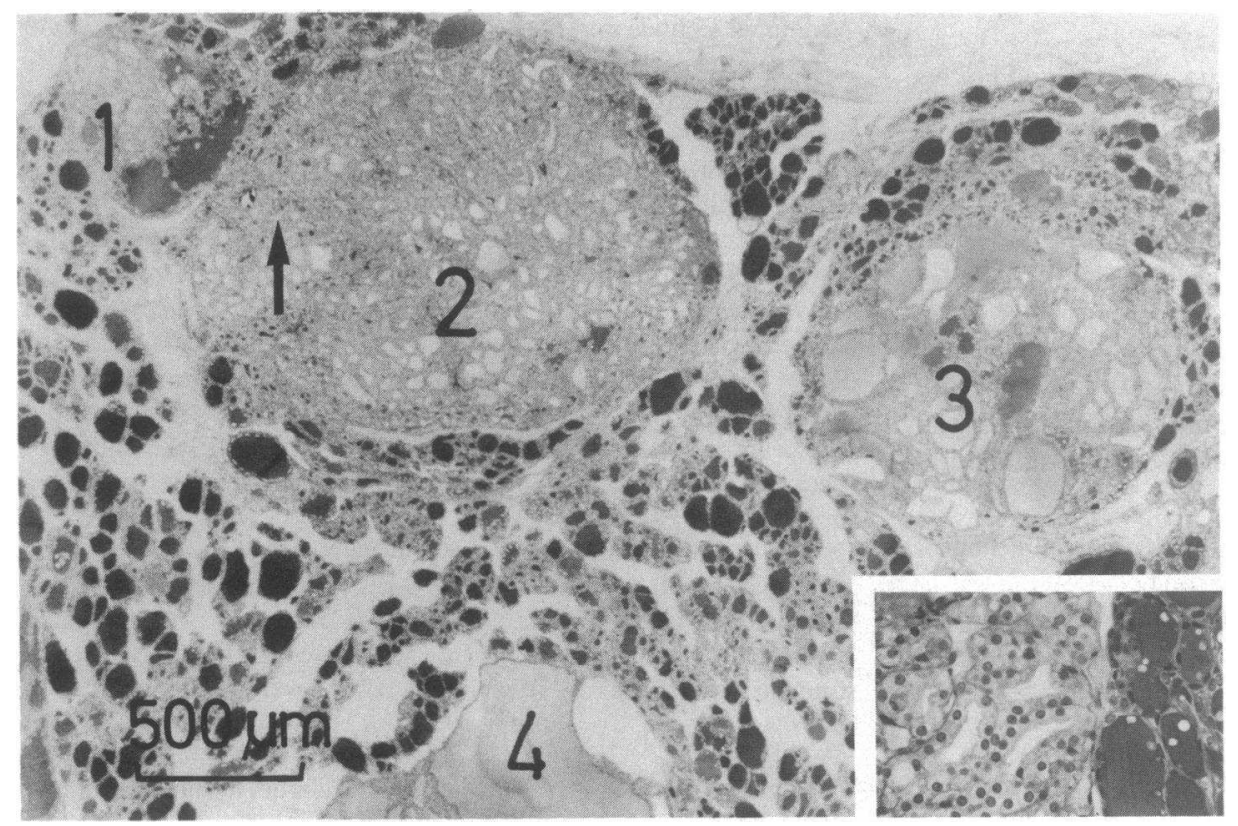

Figure 1. Histologic section across a nodular goiter of a thyrotoxic cat. Four nodules (1-4) consisting of follicles lined by cuboidal epithelial cells with large nuclei (see inset) and filled with pale, barely stained colloid are shown. Some areas within the nodules are almost solid structures with only tiny follicular lumina. Other nodules may contain some large follicles separated by densely cellular parenchyma (3). Occasionally, even a giant follicle may form within the nodules (4). The inset illustrates the large cuboidal cells of a hyperplastic focus lying adjacent to normal follicles. 


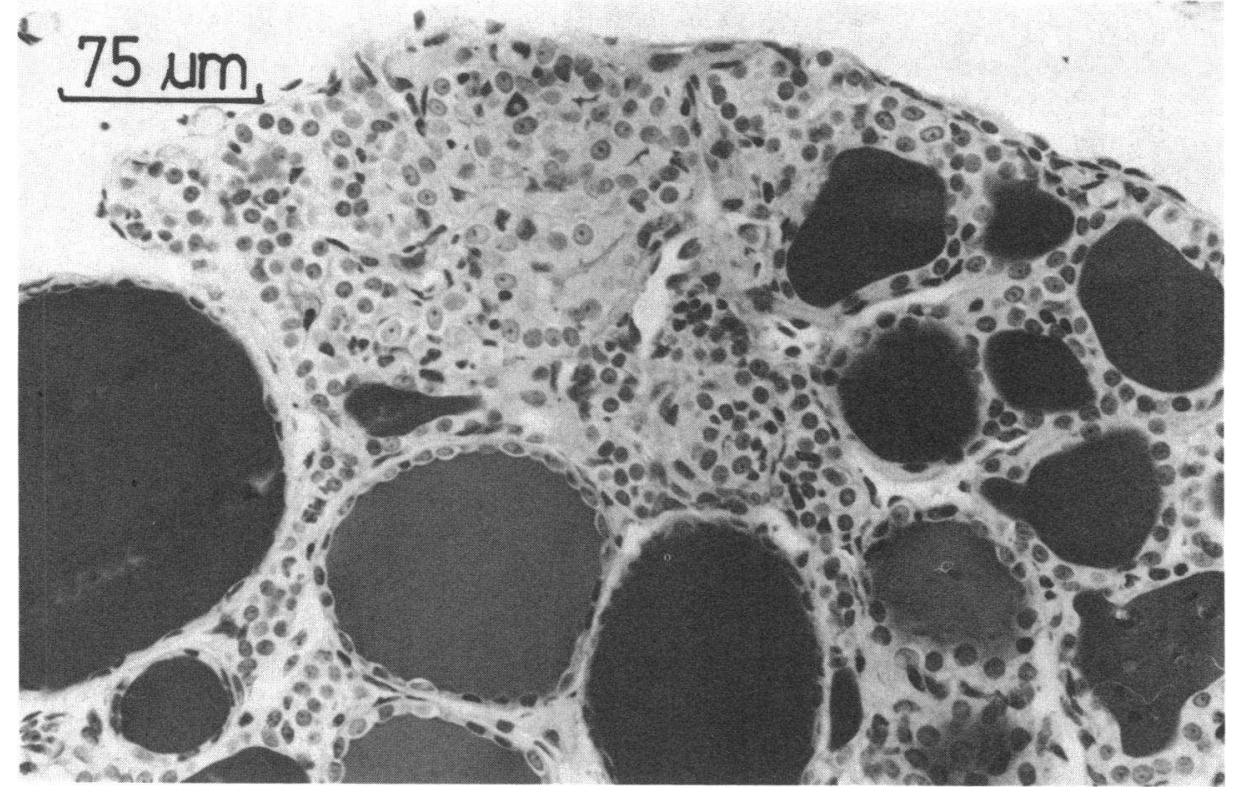

Figure 2. Tiny nest of hyperplastic cuboidal cells surrounded by apparently normal thyroid tissue. Note the smooth transition from normal to hyperplastic tissue at the upper right part of the nodule.

in other species (6), complete suppression of radioiodine uptake was never achieved. The mouse thyroids, with the exception of the TSH-treated group, invariably showed the type of large follicles lined by very flat epithelial cells expected in $\mathrm{T}_{4}$-suppressed normal thyroid tissue.

Sections autoradiographed for assessment of $\left[{ }^{3} \mathrm{H}\right]$ thymidine incorporation, exposed after most of the ${ }^{131} \mathrm{I}$ had decayed, revealed, in the hyperplastic but not in the paranodular goiter tissue, foci of labeled follicular cells proliferating despite the absence of TSH (Fig. 7).

The histologic pattern of grafts from toxic goiters grown in TSH-suppressed mice injected with serum from the hyperthyroid donor cat was not distinguishable from that of grafts grown in animals treated with $\mathrm{T}_{4}$ and injected with sodium chloride only (Fig. 4). This had to be anticipated, since the virtual absence of growth and function in the extranodular tissue provides com- pelling evidence for the lack of a thyroid stimulating factor circulating in the cat's blood. Recent evidence suggests that indeed species specificity is a necessary prerequisite to the demonstration of small amounts of thyroid-stimulating immunoglobulins. We nevertheless confirmed this point by administration of serum from hyperthyroid donor cats to 22 recipient mice. There was no discernible effect on iodine uptake and on the incorporation of $\left[{ }^{3} \mathrm{H}\right]$ thymidine into neither the hyperplastic toxic nodular tissue nor into the paranodular tissue. Likewise, there was no effect of hyperthyroid cat serum on iodine organification in normal cat thyroid xenografts (Fig. 6) or in the hosts' own thyroids. Cat goiter tissue grew remarkably well in the recipient mouse, mostly without any signs of necrosis or nutritional starvation.

Intensity of radioiodine uptake in hyperplastic tissue. Hyperplastic foci contained follicles with many times higher radioiodine content than the follicles in extranodular tissue (Figs.

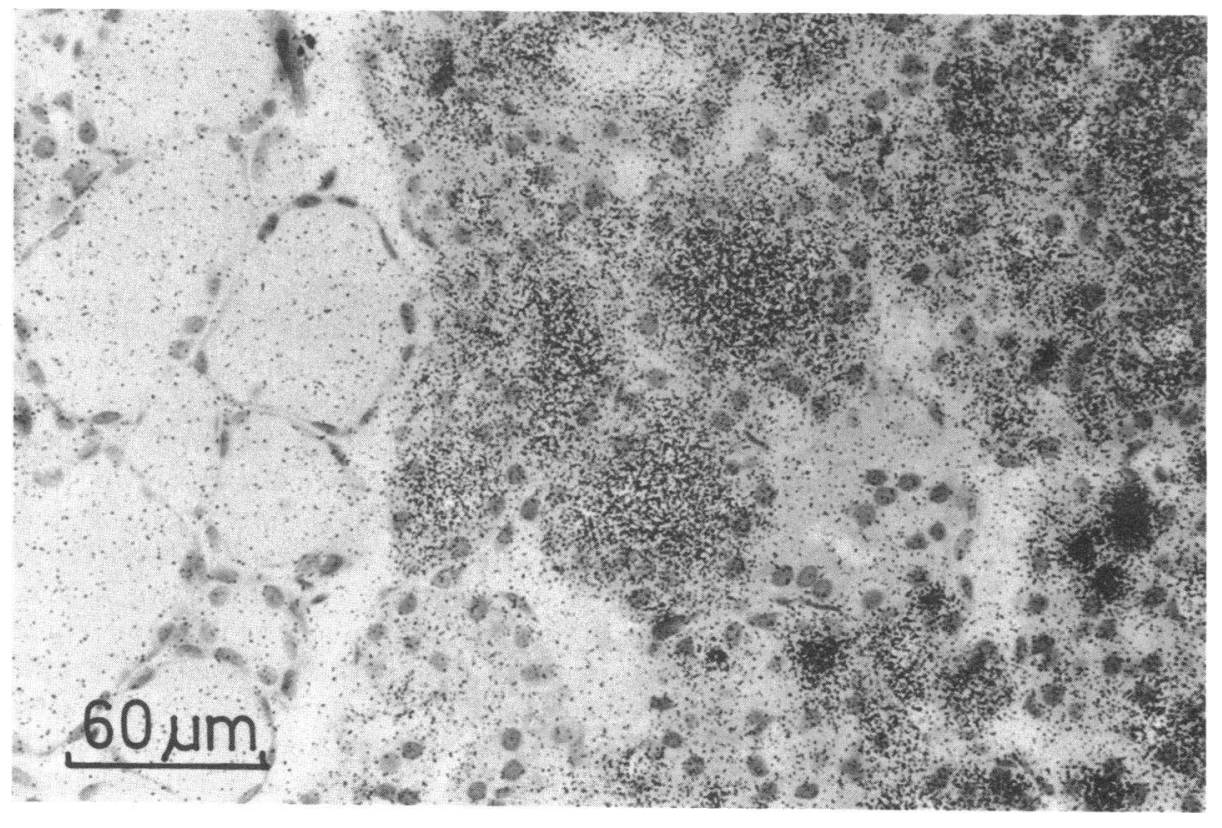

Figure 3. Autoradiograph of a hyperthyroid cat goiter labeled with $20 \mu \mathrm{Ci}$ of ${ }^{125} \mathrm{I}$ for $4 \mathrm{~h}$ before surgery showing intense iodine organification within a hyperplastic nodule and very little iodine uptake within the adjacent paranodular tissue. In some hyperplastic nodules there was considerable heterogeneity of radioiodine organification among individual follicles even within the same nodule. Nuclear fast red stain, exposure time $65 \mathrm{~d}$. 

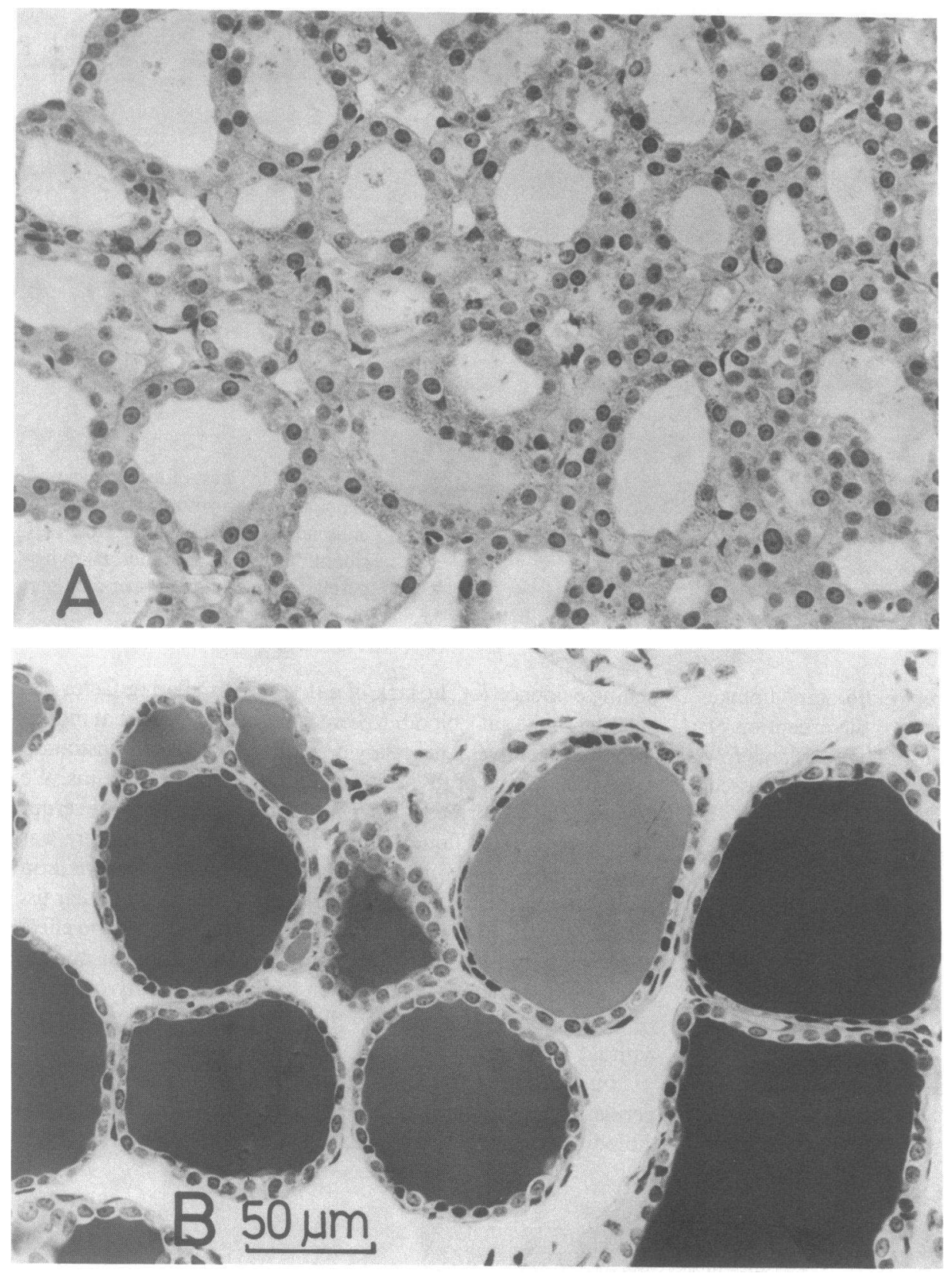

Figure 4. PAS-stained histologic section from a surgical specimen of a toxic goiter of a 12 -yr-old cat $(A, B)$ and a xenograft of the same goiter grown in a T4treated recipient mouse for $6 \mathrm{wk}(C, D)$. $(A)$ A micro- to normofollicular area of a hyperplastic nodule shows columnar follicular cells that contain large nuclei. The intraluminal colloid is faintly PASpositive. (B) An area of paranodular tissue containing follicles with abundant, strongly PAS-positive colloid, lined by a flat epithelium. Note that the ratio between follicular cell volume and follicular colloid volume in the hyperplastic nodules is much higher than in the paranodular tissue. The xenografts from the hyperplastic nodule $(C)$ as well as that from the paranodular area $(D)$ are morphologically almost indistinguishable from their respective mother tissues $(A, B)$.
3, 5). This does not indicate, however, that the individual cells in the hyperplastic tissue also had a higher than normal iodinating capacity. A higher grain count over small follicles after short labeling times is to be expected because of the lower lumen to surface ratio and, therefore, the smaller distribution volume of the tracer (9). Since all thyroid cells have a residual autonomous (i.e., TSH-independent) iodine turnover, although with wide intercellular variations (6), any increase of the total number of thyrocytes must produce more hormone. The large volumes of the hyperplastic nodules together with their higher cellularity thus may easily account for excessive hormone production.

\section{Discussion}

In some geographical areas, aging cats frequently develop toxic multinodular goiters. The etiology of this thyroid disease is un- known. Clinical and scintigraphic observations suggest that the disease does not uniformly involve the entire thyroid gland, but is multifocal in distribution.

The present investigations confirm, by means of histologic and autoradiographic studies of goiter tissue labeled with ${ }^{125} \mathrm{I}$ before surgery, that thyrotoxicosis is the consequence of the multifocal emergence and proliferation of uniformly large cuboidal epithelial cells with a high degree of autonomous iodinating capacity. The particular size and shape of the proliferating cells indicate that a stable change in the phenotype has occurred and that this change is transmitted from mother to daughter cells. This contention is strongly supported by the demonstration that the proliferating cells fully retain their cuboidal shape, their high growth potential and their functional autonomy after transplantation in a nude recipient mouse whose endogenous TSH-secretion is suppressed. Thus, the focally proliferating cells 

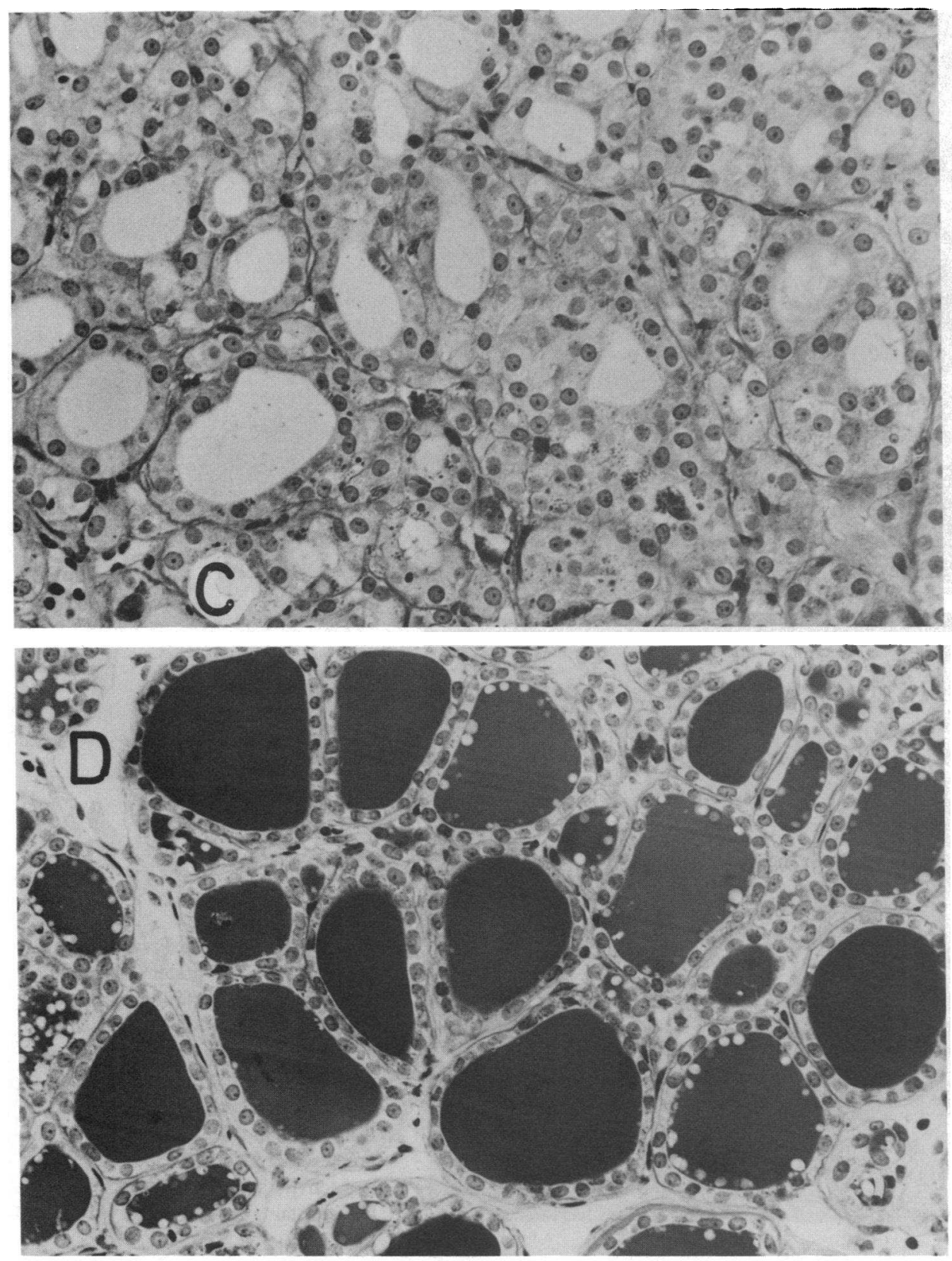

Figure 4 (Continued)

of the cat goiters are not only autonomously growing and functioning in the original thyroid gland but also in a foreign environment.

The hyperplastic foci ranged in size from tiny nests of a few cells to expanding nodules of several centimeters in diameter. In small foci it was often difficult to distinguish between normal and hyperplastic tissue (Fig. 2). In some nodules a stalk region, i.e. a zone of transition where the body of the nodule had apparently grown out of the normal tissue was found. Except for such areas, the large hyperplastic cells of the expanding nodules lay adjacent to the surrounding normal follicles with a sharp boundary between the two tissues (Fig. 1).

Autoradiographic results show that most, though clearly not all, follicles of the hyperplastic nodules have a much higher iodine uptake than the apparently suppressed paranodular tissue. This is true for the original goiter in the thyrotoxic cat as well as for the transplanted tissue in the $T_{4}$-treated mouse. Since TSH is presumably suppressed in both conditions, the observed iodine turnover must truly be "autonomous" (TSH independent). As explained in the result-section, however, hyperplastic cells need not necessarily have a higher degree of autonomous iodinating capacity than normal thyrocytes. Some degree of autonomous iodine turnover is a natural property of most follicular cells (6). Therefore, any increase in the total mass of thyrocytes necessarily increases the amount of hormone autonomously produced in the absence of TSH. The large volume of newly generated cells in the cat goiters may itself explain the excessive hormone production. Since small follicles necessarily have a higher uptake at short time intervals (9) and, in addition, since changes of the hydrodynamic properties of the colloid may greatly alter the 

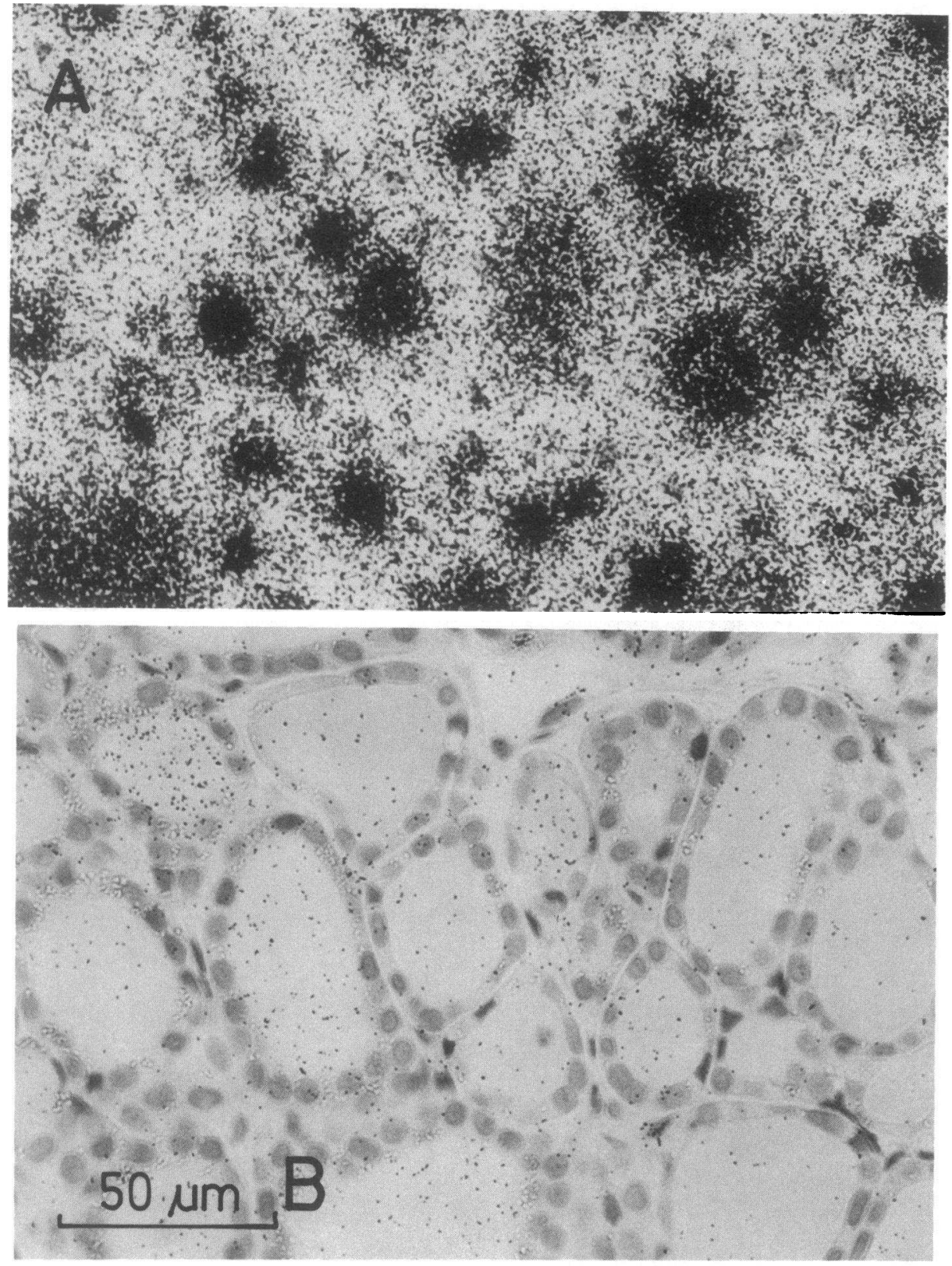

Figure 5. Xenografts of two different areas of a toxic cat goiter grown in a TSH-suppressed host mouse injected with $20 \mu \mathrm{Ci}$ of ${ }^{131} \mathrm{I} 3 \mathrm{~h}$ before killing. The hyperplastic nodular tissue $(A)$ displays intense organification of the radioiodine label, whereas in the graft from the paranodular tissue $(B)$, exposed under identical conditions, much less activity has accumulated. Nuclear fast red stain, exposure time $4 \mathrm{~d}$.

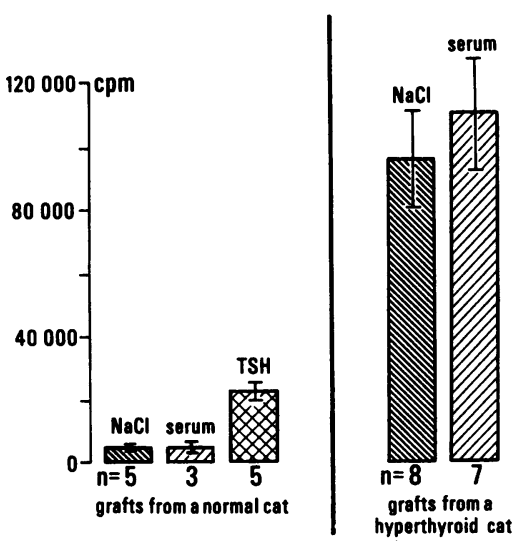

Figure 6. Radioiodine uptake into xenotransplanted normal and toxic goiter tissue growing in $\mathrm{T}_{4}$-treated host mice labeled with 20 $\mu \mathrm{Ci}$ of ${ }^{131} \mathrm{I}$ for $3 \mathrm{~h}$ before sacrifice. ${ }^{131} \mathrm{I}$ uptake (mean \pm SEM) into normal tissue is low in the absence of TSH and is not enhanced by administration of hyperthyroid cat serum, whereas it is readily stimulated by TSH. Toxic goiter tissue shows unabated high autonomous iodine uptake that is not significantly altered by administration of serum from the hyperthyroid donor cat. iodine kinetics (10), the high accumulation of radioiodine within the follicles of the nodules cannot be taken as direct quantitative evidence supporting true hyperfunction of the single cell.

In contrast to findings with human Graves' disease serum $(11,12)$, serum from our donor cats failed to stimulate iodine uptake in xenografts of either goiter or normal tissue. In accord with this, we have been unable to identify a circulating thyroid stimulating agent in cats with hyperthyroidism (Peterson, M. E., and R. S. Brown, unpublished observations).

Even if some kind of thyroid stimulator were present in the cat serum, it could not explain the purely focal nature of the thyroid stimulating agent and account for the persistence of all morphologic and functional characteristics of the xenografted thyroid nodules. Thus, the basic question arises as to the mechanisms that transform only a few selected subsets of follicular cells into autonomously proliferating ones.

At present we have no alternative explanation to that pre- 



Figure 7. Xenograft of a toxic goiter of an 18-yr-old cat grown in a $T_{4}$-treated host mouse injected with $\left[{ }^{3} \mathrm{H}\right]$ thymidine for $3 \mathrm{~d}$ and with ${ }^{131} \mathrm{I}$ for $3 \mathrm{~h}$ before sacrifice. Autoradiograph $A$, taken from a hyperplastic area and exposed $3 \mathrm{mo}$ after radioiodine labeling, shows that despite the absence of TSH a considerable fraction of the follicular cells has incorporated the thymidine label into their nuclei. The grains within the follicular lumina result from residual ${ }^{131}$ I activity. No incorporation of $\left[{ }^{3} \mathrm{H}\right]$ thymidine into follicular cell nuclei is found in autoradiograph $B$ showing a paranodular area, exposed under identical conditions. $\mathrm{Nu}$ clear fast red stain, exposure time $72 \mathrm{~d}$. sented for the pathogenesis of heterogeneous multinodular human goiters $(5,6,13,14)$. We have indeed produced evidence that the propensity to grow is very heterogeneous between different cells of normal thyroid follicles and that some cells have an exceedingly high natural, autonomous growth potential, reminiscent of and possibly related to that characterizing fetal human and mouse thyroid cells (15; Peter, H. J., Studer, H., and P. Groscurth, manuscript submitted for publication). These fast growing cells tend to gradually increase in number with time, thus accounting for the invariable tendency of all slowly growing goiters, and even of normal thyroids, to become nodular in aged individuals. We therefore suggest that the hyperplastic nodules of toxic cat goiters are but late manifestations of the natural phenomenon of an inborn growth advantage in some thyrocytes, possibly resulting from the persistence into adult life of some cells with the typical growth behavior of embryonic cells. It is not clear yet, whether the cells with a high growth propensity have the particular cuboidal shape already within the normal thyroid or, as an alternative, if they may acquire new phenotypic traits that are passed on from the mother to daughter cells. The latter phenomenon is likely to occur in human goiters (6).

\section{Acknowledgments}

The authors would like to thank Mrs. M. Oestreicher for excellent technical assistance.

This work was supported by grant no 3.987 .84 from the Swiss National Science Foundation.

\section{References}

1. Peterson, M. E., D. V. Becker, J. R. Hurley, and D. C. Ferguson. 1980. Spontaneous feline hyperthyroidism. Program of the 62nd Annual Meeting of the Endocrine Society. p. 203. 
2. Holzworth, J., P. Theran, J. L. Carpenter, N. K. Harpster, and R. J. Todoroff. 1980. Hyperthyroidism in the cat: ten cases. J. Am. Vet. Med. Assoc. 176:345-353.

3. Hoenig, M., M. H. Goldschmidt, D. C. Ferguson, K. Koch, and M. J. Eymoutt. 1982. Toxic nodular goiter in the cat. J. Small Anim. Pract. 23:1-12.

4. Peterson, M. E., P. F. Kintzer, P. G. Cavanagh, P. R. Fox, D. C. Ferguson, G. F. Johnson, and D. V. Becker. 1983. Feline hyperthyroidism: pretreatment clinical and laboratory evaluation of 131 cases. J. Am. Vet. Med. Assoc. 183:103-110.

5. Peter, H. J., H. Studer, R. Forster, and H. Gerber. 1982. The pathogenesis of "hot" and "cold" follicles in multinodular goiters. $J$. Clin. Endocrinol. Metab. 55:941-946.

6. Peter, H. J., H. Gerber, H. Studer, and S. Smeds. 1985. Pathogenesis of heterogeneity in human multinodular goiter. J. Clin. Invest. 76:19922002.

7. Weibel, E. R. 1979. Stereological methods. Practical Methods for Biological Morphometry. Vol. 1, Academic Press, London.

8. Burton, K. 1956. A study of the conditions and mechanisms of the diphenylamine reaction for the colorimetric estimation of deoxyribonucleic acid. Biochem. J. 62:315-323.

9. Nadler, N. J., C. P. Leblond, and R. Bogoroch. 1954. The rate of iodine metabolism by the thyroid follicle as a function of its size. Endocrinology. 54:154-172.

10. Gerber, H., H. Studer, and C. von Grünigen. 1985. Paradoxical effects of thyrotropin on diffusion of thyroglobulin in the colloid of rat thyroid follicles after long term thyroxine treatment. Endocrinology. 116: 303-310.

11. Usadel, K. H., P. M. Schumm, H. J. C. Wenisch, F. D. Maul, and $U$. Schwedes. 1985. Transplantation of thyroid tissue to nude mice: a method for demonstrating extrinsic stimulators, and a new bioassay for thyroid stimulating antibodies (TSI). In Current Topics in Thyroid Autoimmunity. D. Doniach, H. Schleusener, and B. Weinheimer, editors. Georg Thieme Verlag, Stuttgart/New York. 187-198.

12. Gerber, H., H. J. Peter, M. P. König, and H. Studer. 1986. Species specific action of Graves' serum on xenotransplanted human thyroid tissue. Ann. Endocrinol. (Paris). 47:16. (Abstr.)

13. Studer, H., and F. Ramelli. 1982. Simple goiter and its variants: euthyroid and hyperthyroid multinodular goiters. Endocrinol. Rev. 3: 40-61.

14. Studer, H., H. J. Peter, and H. Gerber. 1985. Toxic nodular goiter. Clin. Endocrinol. Metab. 14:351-372.

15. Studer, H. 1986. Growth control and follicular cell neoplasia. In New Frontiers in Thyroidology. G. A. Medeiros-Neto, editor. Plenum Press, New York. 131-137. 